\title{
Kasabach-Merritt Syndrome in an Adult
}

\author{
Erişkin Bir Hastada Kasabach-Merritt Sendromu
}

(D) Kolar Vishwanath Vinod, (D) Joseph Johny, (D) Mehalingam Vadivelan, (D) Abdoul Hamide

Jawaharlal Institute of Postgraduate Medical Education and Research (JIPMER), Department of General Medicine, Pondicherry, India

To the Editor,

Kasabach-Merritt syndrome (KMS) is characterized by capillary hemangiomas and consumptive thrombocytopenia and coagulopathy, and may also be associated with microangiopathic hemolysis [1]. KMS is most commonly reported in infants and young children. Here we report a rare case of adult KMS in a 47-year-old woman, giving rise to severe thrombocytopenia and bleeding.

A 47-year-old woman presented with purpuric hemorrhages over her upper and lower limbs and gum bleeds for 8 days. She was found to have two large purple hemangiomas on the tongue (Figure $1 \mathrm{~A}$ ) and a few smaller cutaneous hemangiomas on the face (Figure 1B). These lesions had been present since her childhood and the tongue hemangiomas had enlarged over the past several years. Laboratory evaluation revealed hemoglobin of $89 \mathrm{~g} / \mathrm{L}$, leukocyte count of $9.48 \times 10^{9} / \mathrm{L}$ (leukocyte differential: neutrophils $72 \%$, lymphocytes $25 \%$, eosinophils $2 \%$, basophils $1 \%)$, platelet count of $6 \times 10^{9} / \mathrm{L}$, prothrombin time of $13.4 \mathrm{~s}$ (control: $13 \mathrm{~s}$ ), activated partial thromboplastin time of $32 \mathrm{~s}$ (control: $29 \mathrm{~s}$ ), serum fibrinogen of $1.36 \mathrm{~g} / \mathrm{L}$, elevated fibrin degradation products, positive D-dimer, and normal liver and renal functions. A peripheral blood smear showed normocytic normochromic erythrocytes and markedly reduced platelets. Bone marrow evaluation revealed normal erythropoiesis, myelopoiesis, and megakaryocytic hyperplasia. Contrastenhanced computed tomography of the chest and abdomen excluded deep-seated visceral hemangiomas. She received platelet transfusions and oral tranexamic acid for control of gum bleeds, and she was also started on oral prednisolone at 1 $\mathrm{mg} / \mathrm{kg} / \mathrm{day}$. One month after starting the steroid treatment, the bleeding had stopped and the platelet count had improved to $152 \times 10^{9} / \mathrm{L}$. However, the hemangiomas had remained the same. Considering the risk of traumatic bleeding, she was advised to have surgical excision of the tongue hemangiomas. However, she was unwilling to undergo surgery.

KMS is most commonly reported in infants and only a small percentage $(\sim 0.3 \%)$ of infants with hemangiomas develop KMS [1]. If not recognized and treated in time, KMS may be potentially fatal by causing disseminated intravascular coagulation and severe bleeding, and large hemangiomas can cause high-output cardiac failure and vital organ compression.

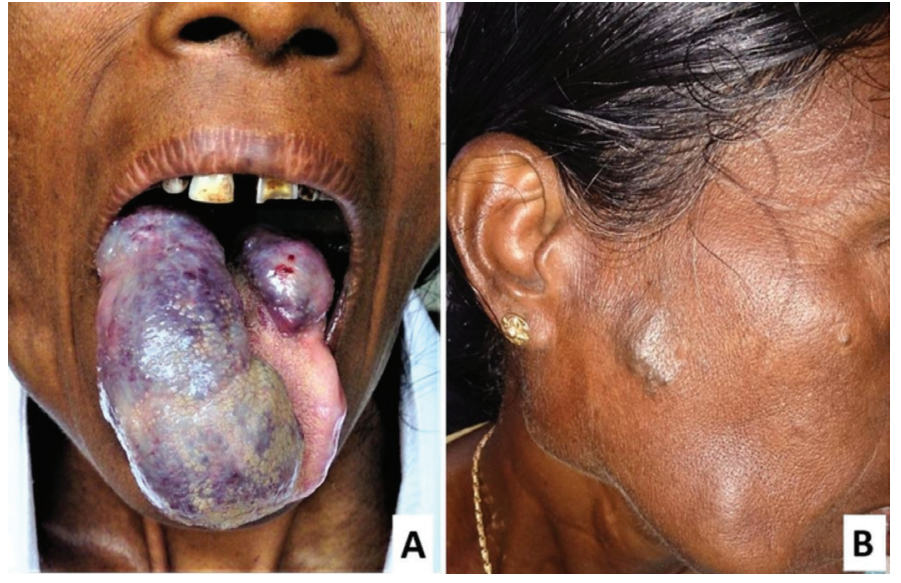

Figure 1. Two large purple hemangiomas of sizes $3 \times 8 \mathrm{~cm}$ and $2 \times 3 \mathrm{~cm}$ on the dorsum of the protruded tongue $(A)$ and a smaller cutaneous hemangioma on the right side of the face (B).

Though rare, KMS has been reported among adults as well $[2,3,4,5]$. The pathogenesis involves activation and consumption of platelets and clotting factors inside hemangiomas, giving rise to consumption coagulopathy and bleeding. However, no correlation has been reported between site, size, and number of hemangiomas and the development of KMS [1]. Cutaneous and visceral hemangiomas have both been implicated in KMS. Work-up in the index patient revealed probable lowgrade disseminated intravascular coagulation, but there was no evidence of microangiopathic hemolysis. Histologically, kaposiform hemangioendotheliomas and tufted angiomas are the most frequent lesions reported in KMS [1]. Treatment options include compression therapy for hemangiomas, surgical excision of large solitary vascular lesions (whenever feasible), or ligation/embolization of feeder vessels when lesions are inaccessible for surgery. Systemic steroids and interferon alfa have shown benefit when vascular lesions are extensive and not amenable to surgery or embolization.

Keywords: Hemangioma, Thrombocytopenia, Coagulopathy, Consumption

Anahtar Sözcükler: Hemanjiom, Trombositopeni, Koagülopati, Tüketim

Informed Consent: Informed consent has been obtained from the patient for publication of her clinical images. 
Conflict of Interest: The authors of this paper have no conflicts of interest, including specific financial interests, relationships, and/or affiliations relevant to the subject matter or materials included.

\section{References}

1. Hall GW. Kasabach-Merritt syndrome: pathogenesis and management. $\mathrm{Br} J$ Haematol 2001;112:851-862.

2. Aslan $A$, Vilsendorf $A M$, Kleine $M$, Bredt $M$, Bektas H. Adult Kasabach-Merritt syndrome due to hepatic giant hemangioma. Case Rep Gastroenterol 2009;3:306-312.

3. Liu X, Yang Z, Tan H, Xu L, Sun Y, Si S, Liu L, Zhou W, Huang J. Giant liver hemangioma with adult Kasabach-Merritt syndrome: case report and literature review. Medicine (Baltimore) 2017;96:e7688.

4. Wu KL, Liao CY, Chang CK, Ho SY, Tyan YS, Huang YC. A huge subcutaneous hematoma in an adult with Kasabach-Merritt syndrome. Am J Case Rep 2017;18:682-686.

5. Oak CY, Jun $\mathrm{CH}$, Cho EA, Lee DH, Cho SB, Park CH, Joo YE, Kim HS, Rew JS, Choi SK. Hepatic hemangioma with Kasabach-Merritt syndrome in an adult patient. Korean J Gastroenterol 2016;67:220-223.

\title{
Spurious Thrombocytosis in the Setting of Hemolytic Anemia and Microcytosis Secondary to Extensive Burn Injury
}

\section{Yaygın Yanık Yaralanmasına Sekonder Gelișen Hemolitik Anemi ve Mikrositoz Zemininde Yalancı Trombositoz}

\author{
(D) Mohammad Faizan Zahid ${ }^{1}$, (D) Mohamed S. Alsammak ${ }^{2}$ \\ ${ }^{1}$ Temple University Hospital, Clinic of Internal Medicine, Philadelphia, Pennsylvania, USA \\ ${ }^{2}$ Temple University Hospital, Clinic of Pathology and Laboratory Medicine, Philadelphia, Pennsylvania, USA
}

To the Editor,

A 57-year-old man was brought to our emergency department from a house fire. On physical examination, he was nonresponsive, hypotensive, and tachycardic with full-thickness skin burns covering the entirety of the body except the lower back ( $>98 \%$ of his body surface area). He was intubated and aggressively resuscitated with IV fluids and multiple pressors for circulatory support.

A complete blood count $(\mathrm{CBC})$ showed normal hemoglobin $(14.5 \mathrm{~g} / \mathrm{dL})$ with leukocytosis $\left(23.6 \times 10^{9} / \mathrm{L}\right)$ and thrombocytosis $\left(979 \times 10^{9} / \mathrm{L}\right)$. Repeat $\mathrm{CBCs}$ also showed thrombocytosis $\left(815 \times 10^{9} / \mathrm{L}\right.$ and $\left.1121 \times 10^{9} / \mathrm{L}\right)$. Microscopic examination of the peripheral blood smear showed widespread red blood cell (RBC) fragmentation, budding, spherocytes, and microspherocytes (Figure 1). Manual platelet count estimates on the peripheral blood smear demonstrated a count of $173 \times 10^{9} / \mathrm{L}$. The patient remained in intractable hypotension and eventually went into cardiac arrest.

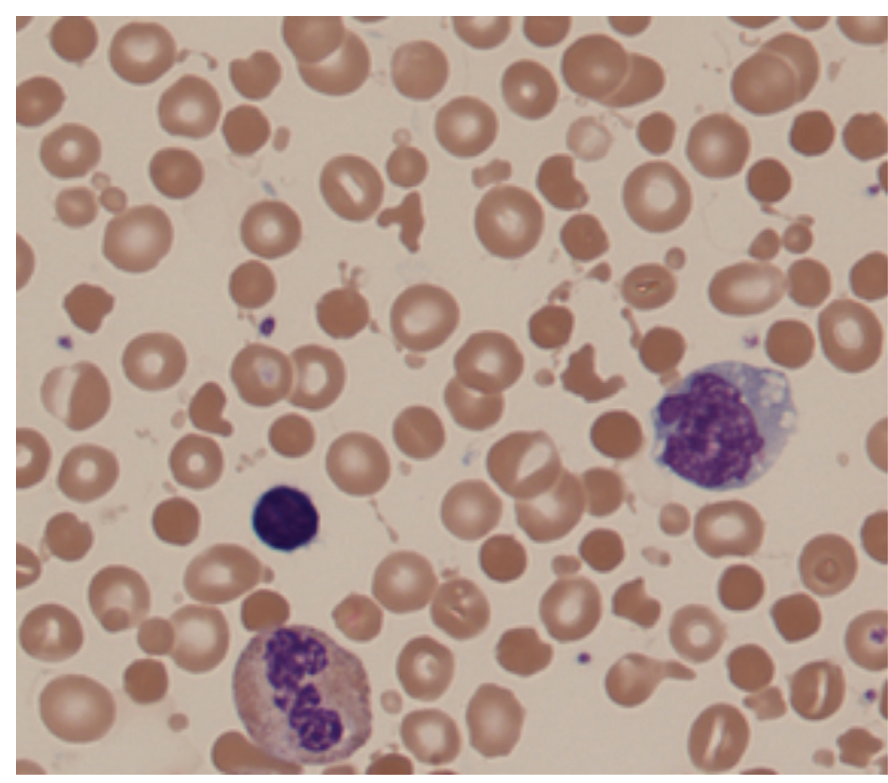

Figure 1. Widespread red blood cell fragmentation, budding, spherocytes, and microspherocytes were revealed by microscopic examination. 